\title{
Pilot Study of Congenital Anomaly Rates at Birth in Fallujah, Iraq, 2010
}

DOI: http://dx.doi.org/10.5915/44-1-10463

\author{
Samira Alaani, MB.Ch.B, D.Ch'; \\ Mohannad A.R. Al-Fallouji, PhD, FRCS (Edin), FRCS (Glas), FRCSI, PD (Law)'; \\ Christopher Busby, BSc, PhD²; Malak Hamdan, M.Eng ${ }^{3}$ \\ ${ }^{1}$ Fallujah General Hospital, Althubbadh, Fallujah, Iraq \\ ${ }^{2}$ Department of Molecular Biosciences, University of Ulster, Coleraine, United Kingdom \\ ${ }^{3}$ The Children's Health Foundation, London, United Kingdom
}

\begin{abstract}
Objectives: To examine numbers of congenital anomaly (CA) at birth overall and by class in one clinic in Fallujah General Hospital, Fallujah, Iraq.

Study Design: All congenital anomaly birth referrals to one pediatric clinician at Fallujah General Hospital for an eleven month period beginning November 1, 2009 were recorded. This clinic was one of three clinics to which cases would be referred.

Results: There were 291 CA cases registered at birth in the period at the study's clinic. The total number of births recorded in the hospital over the period was 6049. The CAs included 113 heart and circulatory system cases, 72 nervous system cases, 40 digestive system cases, 9 genitourinary cases, 6 ear, face and neck cases, 7 respiratory cases and 30 Down syndrome cases.
\end{abstract}

Conclusion: Owing to difficulties establishing the exact number of births from which these cases were drawn, the exact rates cannot be precisely determined. Nevertheless, on the basis of reasonable assumptions relating to the activity of the clinic involved, these results support earlier epidemiological findings. On the basis of work reported elsewhere, the higher rates of congenital anomalies are believed to be caused by exposure to some genotoxic agent, possibly uranium.

Key words: Fallujah, Iraq, congenital anomaly, contamination, heavy metals, depleted uranium

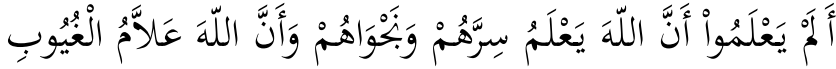

Know they not that Allah knows their secret ideas and their secret counsels and that Allah is the AllKnower of things unseen? ${ }^{1}$
Correspondence should be directed to

Christopher Busby, BSc, PhD

C.Busby@ulster.ac.uk

\section{Introduction}

A previous communication reported results of an epidemiological study in Fallujah, Iraq which revealed very high levels of cancer and 
infant mortality in the period 2005-2010 together with a statistically significant perturbation of the birth sex-ratio of those born from 2005.2 The authors concluded that some genotoxic exposure had occurred at the same time as the United States-led attacks on Fallujah in April and November 2004. Although birth defect data were obtained, that study focused on infant mortality rate as an indicator since that was more easily compared with rates in other control countries. The epidemiological questionnaire/interview approach which had been employed was not suited to comparing congenital anomalies. There is poor standardization of specific anomalies across registers in different countries, which would have made comparison of total anomaly rates at birth problematical. Clinical details of the reported cases were not always available or understood by the Fallujah parents so individual types of anomalies could not be compared.

An attempt to investigate the genetic familial causation of four individual cases of congenital anomaly has subsequently been made. ${ }^{3}$ The authors concluded that in these cases there was no familial genetic basis and that sporadic untargeted effects were responsible, causes which they described as epigenetic.

It was clearly of interest then to further examine the evidence of increased infant mortality and congenital conditions in Fallujah and to investigate the environment for possible agents that may explain the increased incidence of birth defects and cancer rate increases. The environmental aspect of the problem was studied in 2010 when hair sample analysis of 52 elements was carried out on the parents of children diagnosed with congenital anomalies. ${ }^{4}$ In addition soil and water samples were analyzed. Results indicated that man-made slightly enriched uranium was present in soil and in the hair of the parents, with a trend of increasing concentration along the hair strands back to 2005 but that no other genotoxic elements were present which could explain the levels of cancer and congenital disease. ${ }^{4}$ The question of the incidence and types of congenital anomalies remains. Here we address this in a pilot study and report the numbers of different types of congenital anomaly diagnosed in one of three clinics at Fallujah General Hospital (FGH) over an eleven month period in 2009-2010.

\section{Materials and methods}

For 11 consecutive months in 2009 and 2010, all birth defects diagnosed by a single pediatric clinic in FGH were recorded. This enables us to present congenital anomaly numbers in this clinic by specific anomaly. It is clearly of interest to interpret the results in terms of rates per thousand live births, the normal way of assessing congenital anomaly incidence at birth. The total number of births in the hospital was registered and accurately known to be 6049 . The proportion of those births assigned to the specific pediatric clinic was only known to be approximately one third of the total. Children were referred to the pediatric clinic recording the congenital anomaly cases presented in this study on the basis of shift work periods of the pediatrician involved. This represented, in time, slightly less than one third of the total pediatric work in Fallujah General Hospital over the period. Nevertheless, owing to the uncertainty of the numbers of births from which the cases seen at the clinic were drawn, no attempt has been made here to calculate exact rates.

An unknown number of pregnant women were seen at private offices, received prenatal diagnosis of fetal anomaly and were directed to deliver at FGH. While this produces a selection bias, the authors believe it is limited because the few mothers who would go to private offices 
would be directed to deliver at $\mathrm{FGH}$, regardless of whether prenatal diagnosis of anomaly was made or not. In addition, prenatal diagnosis of congenital anomaly in the region served by FGH is limited by the poor quality of the equipment and shortages of trained personnel.

This was a prospective study. Details of all congenital anomalies diagnosed between November 1, 2009 and September 30, 2010 by pediatrician and first author Samira Alaani at Fallujah General Hospital were recorded. These were live born babies with congenital anomalies referred to the pediatric department from the delivery and operation room. There was no bias in the referrals as it was known that all clinics at the hospital saw birth problems on the basis of work periods only; therefore congenital anomaly cases were not more likely to be referred to this clinic due to any special pediatric expertise. The total registered births in the period consisted of 3208 males and 2841 females. Social data for the CA children obtained from the parents of the newborn included birth date, type of delivery, history of consanguinity (defined by first, second and third cousin marriages as reported by parents), previous family history of birth defects, stillbirths and abortions before and after 2004, age and occupation of both parents, history of maternal infection, gestational hypertension and diabetes, harmful or teratogenic drug use, exposure to ionizing radiation during pregnancy and address of the family.

\section{Results}

The numbers of cases of different types of congenital anomaly recorded in the pediatric clinic in Fallujah General Hospital from November 1, 2009 to September 30, 2010 are given in Table. There were 158 males and 129 females. Four newborns had ambiguous genitalia. The families of 156 affected babies were living inside Fallujah, 87 were from villages at the boundaries of Fallujah, and 42 were from Garmah, a town about $16 \mathrm{~km}$ northeast of Fallujah which had been exposed to numerous military operations. Consanguinity, (as defined by marrying first, second or third cousins), was present in $162(56.8 \%)$. A positive family history of congenital anomaly developed before year 2003 was detected in 14 of the 291 cases. Seventeen cases had siblings affected with congenital malformations born after 2004 and had no previous family history. One of the anencephaly cases had a history of 3 previous successive premature deliveries with the same anomaly, all born after 2005. Thirty-three cases (11.6\%) had multiple congenital anomalies involving 2 or more systems.

In this series there was also a twin delivery of a female and male, both having hydrocephaly with spina bifida and meningiocele (female) and posterior encephalocele (male) with absolutely negative prior family history for such anomalies, no maternal infection history and no X-ray radiation exposure during pregnancy. In addition, the mother reported using folic acid supplements for 6 months of her pregnancy.

Forty-four cases reported a history of previous spontaneous abortion, with only 7 before 2004. A history of stillbirth siblings was reported in 7 cases, all born after 2004. The median maternal age at delivery was 26.7 years. Forty-four of the 291 patients died. Forty were neonatal deaths, and the remaining four died within the first year of life.

There were 37 stillbirths in the delivery room during the study. The causes of the stillbirths are unknown. They are not included in the study. 
Table. Number of Babies with Congenital Anomalies and Their Types in the Study Clinic in Fallujah General Hospital, November 1, 2009 to September 30, 2010.

\begin{tabular}{|c|c|c|}
\hline & $\begin{array}{l}\text { Number of } \\
\text { Anomalies }\end{array}$ & $\begin{array}{c}\text { Number of } \\
\text { Babies }\end{array}$ \\
\hline All babies & & 291 \\
\hline Cardiovascular system & & 113 \\
\hline Ventricular septal defect VSD & 50 & \\
\hline Atrial Septal Defect ASD & 47 & \\
\hline Tetrology of Fallot TOF & 9 & \\
\hline Patent Ductus Arteriosus PDA & 13 & \\
\hline Transposition of Great Arteries TGA & 10 & \\
\hline Mitral valve disease & 3 & \\
\hline Single ventricle & 2 & \\
\hline Tricuspid atresia & 1 & \\
\hline Cardiomyopathy & 1 & \\
\hline Total & 136 & \\
\hline Central Nervous system & & 72 \\
\hline Digestive system & & 40 \\
\hline Genitourinary & & 9 \\
\hline Ear, face and neck & & 6 \\
\hline Respiratory & & 7 \\
\hline Chromosomal and genetic syndromes & & 44 \\
\hline Down & 30 & \\
\hline Albert & 1 & \\
\hline Pierre Robin & 1 & \\
\hline Holt Oram & 1 & \\
\hline Achondroplasia & 1 & \\
\hline Icthyosis & 1 & \\
\hline Epidermolysis bullosa & 2 & \\
\hline Hirschprung disease & 2 & \\
\hline Thanatophoric displasia & 5 & \\
\hline Total & 44 & \\
\hline
\end{tabular}

\section{Discussion}

Between April and December 2004, Fallujah was the site of two major battles. According to the experience of all pediatricians in Fallujah, there was a dramatic increase in the prevalence of congenital malformations after that period.
However, despite anecdotal evidence and widespread media reporting, no formal scientific study was undertaken until early 2010 when a survey epidemiological study was carried out. ${ }^{2}$ The findings of this study were remarkable. There was a 4-fold excess of infant mortality in 
the period 2005-2010. There was a significant perturbation of the sex-ratio resulting in fewer boys born, and there was a large increase in cancer rates. The sex ratio change, a wellaccepted indicator of genetic damage to a population, began in 2005 in the cohorts born after the attacks on the city in 2004. However, although all the findings were highly statistically significant, the epidemiological study suffered from various structural problems, and the number of individuals included was modest. In addition, congenital malformation prevalence rates were not reported owing to the fact that clinical data were not available. It was therefore of some importance to follow up with a more formal investigation of congenital anomalies. Results are presented here. They appear to support the conclusions of the epidemiological study. ${ }^{2}$ The latter found an infant mortality rate of 80 per thousand live births over the period 2005-2010 which was believed to be driven by congenital anomalies. This is confirmed by the numbers of congenital anomalies recorded in the pediatric department of Fallujah General Hospital and presented here. Since the clinic sees approximately one third of the referrals from the delivery room and we know from the birth records that 6049 births occurred in the period, we can make a scoping and approximate assessment of the overall rates. Since there were 291 cases, the rate cannot be less than 48 per 1000 births even if no other cases were referred to any of the two other clinics at the hospital. Assuming that the clinic saw one third of the referrals from the delivery room, the rate would have been 144 per 1000 births. A rate of between 48 and 144 per 1000 births may be compared with Giza, Egypt (31.7), ${ }^{5}$ Kuwait (12.5) ${ }^{6}$ and the United Arab Emirates (7.9).?

Congenital anomalies are part of a spectrum of adverse pregnancy outcomes that may be associated with exposure to environmental pollution. ${ }^{8,9}$ This spectrum also includes fetal death, including early spontaneous abortion, low birth weight associated with prematurity or intrauterine growth retardation, and neurodevelopmental and congenital heart and circulatory system effects that can only be detected in later infancy and childhood. Since the results reported here are for infants at or shortly after birth, later diagnosed congenital heart and circulatory system disorders can only add to the high apparent rates found. Environmental pollution can cause congenital anomalies through preconceptional mutagenic action (maternal or paternal) or postconceptional teratogenic action (maternal). Preconceptional mutagenic effects may include chromosomal anomalies and syndromes as a result of new mutations. ${ }^{8}$ For example, Downs syndrome increases have been reported in studies of those exposed to ionizing radiation ${ }^{10,11}$ and Chernobyl fallout ${ }^{12,13}$ although there is some uncertainty ${ }^{146}$ about overall effects in Europe. Postconceptional action depends on the precise timing of exposure. In embryonic and fetal development, each normal developmental process occurs during a specific period of a few days or weeks, and it is during this 'sensitive period' that exposure to a teratogenic agent may lead to an anomaly. A particular chemical may cause a congenital anomaly after exposure in, say, the sixth week of development, but exposure during the previous or succeeding week may have no effect or an anatomically distinct effect. ${ }^{8}$ Where a child has more than one anomaly ('multiply malformed'), this may be because exposure has covered a number of sensitive periods for different congenital anomalies or because exposure at one developmental stage has a number of different effects on organogenesis. Increased prevalence 
of congenital anomalies is associated with proximity to hazardous chemicals. ${ }^{8,9}$

The findings of our epidemiological survey showed very high levels of cancer. For children 0-14 the Relative Risk (using Egypt as a control) was 14. For all leukemias, age 0-34 years the Relative Risk was $38 .{ }^{2}$ These large effects might provide a valuable clue for cancer researchers in that it may lead them to identifying a major cause of childhood and adult cancer. The genetic basis of cancer is now universally agreed, and the genotoxic stress in Fallujah which led to the high cancer rates and sex ratio changes in the epidemiology study are supported here by the changes in the levels of congenital anomaly. These high levels of birth defects have, of course, been the subject of many media stories, as have the increases of cancer in Iraq. But we can now say that these anecdotal reports seem backed by evidence provided by this pilot study.

The analysis of hair and environmental samples reported elsewhere ${ }^{4}$ already show that one possible cause of these effects is exposure to the effects of or fallout from some weapon which either uses or produces slightly enriched uranium. This issue will not be discussed further here. The purpose of the present pilot study was to ask if there are high levels of congenital anomalies in Fallujah and to see if it were worth taking the matter further with a more formal study.

\section{Conclusions}

The evidence of high congenital anomaly birth rates from this pilot study of one of three clinics at Fallujah General Hospital supports the contention that some serious mutagenic exposure has affected and still affects the population of the town in 2010. Following this initial pilot study, further formal epidemiological investigations are planned.

\section{Acknowledgements and conflict of interest}

None of us has any conflict of interest. We are grateful to the Children's Health Foundation London for assistance towards the cost of analytical measurements and the International Foundation for Research on Radioactivity Risk, Stockholm for assistance towards equipment costs.

\section{References}

1. The Glorious Quran, Chapter 9, Verse 78.

2. Busby C, Hamdan M, Ariabi E. Cancer, infant mortality and birth sex-ratio in Fallujah, Iraq 2005-2009. Int J Environ Res Public Health. 2010;7:2828-37. http://doi.org/ck8j8z

3. Alaani S, Savabieasfahani M, Tafash $\mathrm{M}$ et al. Four polygamous families with congenital birth defects from Fallujah Iraq. Int J Environ Res Public Health. 2011;8:89-96. http://dx.doi.org/10.3390/ijerph8010089

4. Alaani S, Tafash M, Busby C, et al. Uranium and other contaminants in hair from the parents of children with congenital anomalies in Fallujah, Iraq. Confl Health. 2011;5:15. http://dx.doi.org/10.1186/1752-1505-5-15

5. Temtamy SA, Abdel Meguid N, Mazen I, et al. A genetic epidemiological study of malformations at birth in Egypt. Eastern Mediterranean Health Journal. 1998;4:252-9. http://bit.ly/PAuRed

6. Madi SA, Al-Naggar RL, Al-Awadi SA, et al. Profile of major congenital malformations in neonates in Al-Jahra region of Kuwait. Eastern Mediterranean Health Journal. 2005; 11: 700-6. PMID: 16700386 http://bit.ly/O6rZXE

7. al-Gazali LI, Dawodu AH, Sabarinathan K, et al. The profile of major congenital abnormalities in the United Arab Emirates (UAE) population. J Med Genet. 1995; 32: 7-13. http://dx.doi.org/10.1136/jmg.32.1.7

8. Busby A. Hazardous waste and congenital anomalies. In: Wilkinson P, editor. 
Environmental epidemiology. Maidenhead UK: Open University Press; 2006:93-106.

9. Dolk H, Vrijheid M, Armstrong B, et al. Risk of congenital anomalies near hazardous-waste landfill sites in Europe: the EUROHAZCON study. Lancet. 1998;352:423-7. http://doi.org/c2zwXz 10. Bound JP, Francis BJ, Harvey PW. Down's syndrome: prevalence and ionising radiation in an area of north-west England 1957-91. J Epidemiol Community Health. 1995; 49: 164-70 http://dx.doi.org/10.1136/jech.49.2.164

11. Kochupillai N, Verma IC, Grewal MS, et al. Down's syndrome and related abnormalities in an area of high background radiation in coastal Kerala. Nature. 1976;262:60-1. http://dx.doi.org/10.1038/262060a0

12. Busby C, Lengfelder E, Pflugbeil S, et al. The evidence of radiation effects in embryos and fetuses exposed to Chernobyl fallout and the question of dose response. Med Confl Surviv.
2009;25:20-40. http://doi.org/dxgcjs

13. Zatsepin I, Verger P, Robert-Gnansia E, et al. Down syndrome time-clustering in January 1987 in Belarus: link with the Chernobyl accident? Reprod Toxicol. 2007;24:289-95. http://dx.doi.org/10.1016/j.reprotox.2007.06.003 14. Ramsay CN, Ellis PM, Zealley H. Down's syndrome in the Lothian region of Scotland -1978 to 1989. Biomed Pharmacother. 1991;46:26772. http://doi.org/dfs2z6

15. Burkart W, Grosche B, Schoetzau A. Down's syndrome clusters in Germany after the Chernobyl accident. Radiat Res. 1997;147:321-8. http://dx.doi.org/10.2307/3579339

16. Dolk H, Nichols R. Evaluation of the impact of Chernobyl on the prevalence of congenital anomalies in 16 regions of Europe. EUROCAT Working Group. Int J Epidemiol. 1999;28:941-8. http://dx.doi.org/10.1093/ije/28.5.941 